\title{
Prevalence and factors associated with H. pylori infection in Saudi patients with dyspepsia
}

\author{
Mohammed Akeel ${ }^{1}$, Erwa Elmakki ${ }^{2}$, Atef Shehata ${ }^{3,4}$, Ahmed Elhafey $^{5,6}$, Thanaa Aboshouk ${ }^{7}$, Hussein Ageely ${ }^{2}$, \\ Mohammed Salih Mahfouz ${ }^{8}$
}

\footnotetext{
${ }^{1}$ Department of Anatomy, Faculty of Medicine, Jazan University, Jazan, Kingdom of Saudi Arabia

${ }^{2}$ Department of Internal Medicine, Faculty of Medicine, Jazan University, Jazan, Kingdom of Saudi Arabia

${ }^{3}$ Department of Microbiology and Immunology, Faculty of Medicine, Jazan University, Jazan, Kingdom of Saudi Arabia

${ }^{4}$ Department of Microbiology and Immunology, Faculty of Medicine, Suez Canal University, Ismailia, Egypt

${ }^{5}$ Department of Pathology, Faculty of Medicine, Jazan University, Jazan, Kingdom of Saudi Arabia

${ }^{6}$ Department of Pathology, Faculty of Medicine, Al-Azhar University, Cairo, Egypt

${ }^{7}$ Department of Clinical Biochemistry, Faculty of Medicine, Jazan University, Jazan, Kingdom of Saudi Arabia

${ }^{8}$ Associate Professor, Department of Family and Community Medicine, Faculty of Medicine, Jazan University, Jazan, Kingdom of Saudi Arabia
}

\section{Type of article: Original}

\begin{abstract}
Background: Helicobacter pylori (H. pylori) is a major cause of peptic ulcer disease (PUD) and chronic active gastritis that may progress to gastric cancer. Globally, it has been estimated that $50 \%$ or more of the world's population is infected by $\mathrm{H}$. pylori, making it the most widespread infection across the globe.

Objectives: To determine the prevalence of $\mathrm{H}$. pylori infection and to identify factors associated with $\mathrm{H}$. pylori infection in Saudi patients presenting with dyspepsia.

Methods: In this prospective cross-sectional study, a total of 404 gastric biopsies were endoscopically obtained from 404 patients with dyspepsia from September 2014 to April 2016 (Jazan Province, Saudi Arabia). The specimens were analyzed using the real-time polymerase chain reaction (PCR). The data was examined using descriptive statistics as well as determining the prevalence, and employing Chi square and Fisher exact test. A pvalue of $\leq 0.05$ was considered statistically significant in examining the research hypotheses.

Results: The overall prevalence of $\mathrm{H}$. pylori in Jazan Province was 46.5\% (95\% CI: 41.7-51.4) and the prevalence was lower among those $>55$ years old. Prevalence was higher among urban $(50.0 \%$; 95\% CI: 43.1 56.8 ) versus rural $(42.1 \%$; 95\% CI: 35.1-49.3), but with no significant difference. Prevalence did not show significant difference among different Body Mass Index (BMI) categories, ranging from $40.2 \%$ to $47.7 \%$. The prevalence of $\mathrm{H}$. pylori in females was $47.1 \%$ (95\% CI: $40.4-53.9)$ versus $45.6 \%$ (95\% CI: $38.7-52.6)$ in males. Histopathology findings were associated with $\mathrm{H}$. pylori infection with prevalence of $58.1 \%$ among patients with chronic active gastritis, compared to $24.1 \%$ and $34.8 \%$ among mild and chronic gastritis, respectively.

Conclusion: Our results indicate that there is a high prevalence of H. pylori among Saudi patients with dyspepsia. Prevalence of H. pylori was high in ages below 55 years. Chronic active gastritis was significantly associated with H. pylori infection. In depth studies are needed to determine associated factors with of $\mathrm{H}$ pylori infection in the region

Keywords: H. pylori, PCR, Prevalence, Jazan province
\end{abstract}

\section{Corresponding author:}

Associate Professor Dr. Mohammed Salih Mahfouz, Department of Family and Community Medicine, Faculty of Medicine, Jazan University, Jazan, Kingdom of Saudi Arabia.

Tel: +966.561120210, Email: mmahfouz@jazanu.edu.sa and mm.mahfouz@gmail.com

Received: October 22, 2017, Accepted: June 02, 2018, Published: September 2018

iThenticate screening: May 30, 2018, English editing: July 17, 2018, Quality control: July 19, 2018

Funding and ethics committee approval: Jazan University (Ref: FMRERC-2012)

(C) 2018 The Authors. This is an open access article under the terms of the Creative Commons Attribution-NonCommercialNoDerivs License, which permits use and distribution in any medium, provided the original work is properly cited, the use is non-commercial and no modifications or adaptations are made. 


\section{Introduction}

H. pylori (HP) is spiral-shaped gram-negative bacterium, known to colonize, mainly the antral portion of the human gastric mucosa. H. pylori infection is correlated with the development of chronic active gastritis, peptic ulcer disease; mucosa associated lymphoid tissue lymphoma (MALT) and gastric adenocarcinoma $(1,2)$. Globally, it has been estimated that $50 \%$ or more of the world's population is infected by H. pylori, making it the most widespread infection across the globe $(1,2)$. Actual infection rates vary from one country to another however, the developing world has much higher infection rates than the developed one (3). On the other hand, up to $85 \%$ of individuals infected with $\mathrm{H}$. pylori are asymptomatic and have no complications (4). H. pylori infection has been reported to be hyper- endemic in Saudi Arabia. Some studies on H. pylori in Saudi Arabia have shown a high prevalence in various age groups of patients, including individuals with non-ulcer dyspepsia (5). More recent studies on H. pylori infection among Saudi children had shown high infection prevalence among Saudi children in the cities of Jeddah and Riyadh (6). The World Health Organization (WHO) considers H. pylori as a carcinogen (7). It has been reported that infection with $\mathrm{H}$. pylori accounts for $75 \%$ of non-cardia gastric malignancy worldwide (8). The H. pylori-induced gastritis can lead to atrophic gastritis. Atrophic gastritis in turn may progress to intestinal metaplasia, dysplasia and neoplasia, gastric adenocarcinoma and mucosa-associated lymphoid tissue (MALT) lymphoma $(1,9,10)$. Although there are many studies on $\mathrm{H}$. pylori prevalence conducted in different regions of Saudi Arabia $(5,6,11-15)$, few studies have been conducted in Jazan province dealing with $\mathrm{H}$. pylori infection (14). The objectives of this study were to evaluate the prevalence of $\mathrm{H}$. pylori infection in patients presenting with dyspepsia and to identify factors associated with H. pylori infection in Jazan province, south west Saudi Arabia.

\section{Material and Methods}

\subsection{Setting, sampling, and selection criteria}

A prospective cross-sectional study was conducted in Jazan province during the period from September 2014 to April 2016. A sample size of 440 was calculated to conduct this study building on prevalence of $\mathrm{H}$. pylori in Jazan $60 \%$ (14), $95 \%$ confidence interval, error not more than 5\% and nonresponse rate of $15 \%$. The main inclusion criterion in this study was patients 12 years and above with dyspepsia who were willing to participate in the study, while those who received proton pump inhibitors (PPI) two weeks before endoscopy were excluded from the study. Gastric biopsies were collected from all study participants, using upper gastrointestinal endoscopy during the study period at different hospitals in Jazan province.

\subsection{Measures}

\subsubsection{Checklist}

In addition to clinical data, the study collected information related to H. pylori from all participants. Information involved age, gender, and upper gastrointestinal symptoms, symptoms related to other systems, level of education, occupation, living standard, history of smoking, khat use, alcohol intake, Body Mass Index (BMI), past medical history and drug history. Trained nurses were responsible for collecting such information; some information was filled using the patients' medical records. The BMI was categorized according to World Health Organization (WHO) guidelines. These guidelines suggest that individuals with $\left(\mathrm{BMI}<16.0 \mathrm{~kg} / \mathrm{m}^{2}\right)$ are severely underweight, $\left(\mathrm{BMI}=16.0-18.4 \mathrm{~kg} / \mathrm{m}^{2}\right)$ as underweight, $\left(\mathrm{BMI}=18.5-24.9 \mathrm{~kg} / \mathrm{m}^{2}\right)$ as normal weight, $\left(\mathrm{BMI}=25.0-30.0 \mathrm{~kg} / \mathrm{m}^{2}\right)$ as overweight, and (BMI $\geq 30.0 \mathrm{~kg} / \mathrm{m}^{2}$ ) as obese.

\subsubsection{Histopathological examination}

A total of 404 gastric biopsies were examined using the routine hematoxylin and eosin (H\&E) stain to study histopathological changes.

2.2.3. Detection of H. pylori using real time PCR

All gastric biopsies obtained from the study population were submitted for DNA extraction using the DNeasy blood \& tissue kit (Qiagen). All extracted DNA samples were tested for H. pylori by real time PCR amplification using primer-probe based "genesig Quantification of Helicobacter pylori" kit (Primerdesign Ltd., UK). The $20 \mu 1$ reaction mixture consisted of $3 \mu \mathrm{l}$ of the extracted DNA, $10 \mu \mathrm{l}$ of "oasig ${ }^{\mathrm{TM}} 2 \times$ qPCRMastermix" (Primerdesign Ltd.), $1 \mu \mathrm{H}$. pylori specific primer/probe mix, $1 \mu 1$ internal control primer/probe mix, $2 \mu 1$ of internal control DNA, and $3 \mu 1$ RNase/DNase free water supplied with the kit. The reactions were performed using the SmartCycler (Cepheid, Italy). Each PCR run contained positive control (H. pylori DNA supplied with the kit) and negative control (RNase/DNase free water instead of template DNA) reactions. The PCR cycling conditions were according to manufacturer's protocol. 


\subsection{Data management and statistical analysis}

Data were analyzed by IBM $\odot$ SPSS $\odot$ Statistics version 20 (IBM@ Corp., Armonk, NY, USA), using descriptive statistics, prevalence, Chi square and Fisher exact test. The Yates correction term was also used to ensure the accuracy of the Chi square test. P-values less than 0.05 were used to indicate statistical significance.

\subsection{Ethical Considerations}

The study was approved by the research ethics committee (REC) at Faculty of Medicine - Jazan University (Ref: FMRERC-2012). Written consent was obtained from all the participants prior to enrollment. Purpose, potential risk and benefits of the study were communicated in the Arabic language, and consent was documented for all study participants.

\section{Results}

The response rate was $91.8 \%$ (404 out of 440) patients. Table 1 provides background characteristics of the study participants including age, gender, education, etc. The table showed that most participants (39.9\%) were (25-39) years old, (33.9\%) were housewives, and (50.5\%) lived in rural areas and $20.5 \%$ were smokers. Underweight patients accounted for $4.2 \%$, and obese patients were $21.8 \%$ of the group. The mean weight for males $(71.7 \mathrm{~kg})$ and females $(67.5 \mathrm{~kg})$ showed significant differences $(\mathrm{p}<0.05)$. The mean BMI for all study participants was 27.4 $\left(\mathrm{kg} / \mathrm{m}^{2}\right)$ with no significant difference between males and females (Table 1). Table 2 shows H. pylori among the sample of patients. The overall prevalence of H. pylori in Jazan Province was (46.5\%; $95 \%$ CI, 41.7-51.4) and lower among those $>55$ years old. Prevalence was higher among urban (50.0\%) (95\% CI: 43.1-56.8) versus rural (42.1\%) (95\% CI: 35.1-49.3); but with no significant difference. Prevalence according to BMI did not show significant difference among different BMI categories ranging from $40.2 \%$ to $47.7 \%$. H. pylori according to gender showed prevalence among males (45.6\%) (95\% CI: 38.7-52.6) versus females (47.1\%) (95\% CI: 40.4-53.9). Table 3 presents factors that may be associated with $\mathrm{H}$. pylori infection among the study population. According to the table, age was significantly associated with $\mathrm{H}$. pylori infection. The prevalence of $\mathrm{H}$. pylori infection is declined by increase in age, the prevalence among age group (13-29) years is $53.3 \%, 47.0 \%$ among the age group (30-49) years and $36.4 \%$ among the population 50 years and above. Histopathology findings were also associated with $\mathrm{H}$. pylori infection with a prevalence of $58.1 \%$ among patients with chronic active gastritis, compared to $24.1 \%$ and $34.8 \%$ among mild and chronic gastritis, respectively.

Table 1. Socio-demographic description of the studied patients

\begin{tabular}{|l|l|l|l|}
\hline Characteristics & & $\mathrm{n}$ & $\%$ \\
\hline Age groups (year) & $13-24$ & 58 & 14.4 \\
\cline { 2 - 4 } & $25-39$ & 161 & 39.9 \\
\cline { 2 - 4 } & $40-54$ & 142 & 35.1 \\
\cline { 2 - 4 } & $\geq 55$ & 35 & 8.7 \\
\cline { 2 - 4 } & Not stated & 8 & 2.0 \\
\hline \multirow{5}{*}{ Gender } & Male & 194 & 48.0 \\
\cline { 2 - 4 } & Female & 207 & 51.2 \\
\cline { 2 - 4 } & Not Stated & 3 & 0.7 \\
\hline Place of Residence & Urban & 185 & 45.8 \\
\cline { 2 - 4 } & Rural & 204 & 50.5 \\
\cline { 2 - 4 } & Not Stated & 15 & 3.7 \\
\hline Smoking & Yes & 83 & 20.5 \\
\cline { 2 - 4 } & No & 313 & 77.5 \\
\cline { 2 - 4 } & Not Stated & 8 & 2.0 \\
\hline Khat chewing & Yes & 87 & 21.5 \\
\cline { 2 - 4 } & No & 308 & 76.2 \\
\cline { 2 - 4 } & Not Stated & 9 & 2.2 \\
\hline BMI Categories & Underweight & 17 & 4.2 \\
\cline { 2 - 4 } & Normal weight & 90 & 22.3 \\
\cline { 2 - 4 } & Overweight & 88 & 21.8 \\
\cline { 2 - 4 } & Obese & 88 & 21.8 \\
\cline { 2 - 4 } & Not stated & 121 & 30.0 \\
\hline Total & & 404 & 100 \\
\hline
\end{tabular}


Table 2. Prevalence of $\mathrm{H}$. pylori among sample of patients

\begin{tabular}{|c|c|c|c|c|}
\hline \multicolumn{2}{|l|}{ Characteristics } & Prevalence & $95 \% \mathrm{CI}$ & p-value \\
\hline \multirow[t]{4}{*}{ Age groups (year) } & $13-24$ & 50.0 & $37.5-62.5$ & \multirow[t]{4}{*}{0.014} \\
\hline & $25-39$ & 49.7 & $42.0-57.3$ & \\
\hline & $40-54$ & 50.0 & $40.8-60.1$ & \\
\hline & $\geq 55$ & 29.5 & $20.5-40.4$ & \\
\hline \multirow[t]{2}{*}{ Gender } & Male & 45.6 & $38.7-52.6$ & \multirow[t]{2}{*}{0.765} \\
\hline & Female & 47.1 & $40.4-53.9$ & \\
\hline \multirow[t]{2}{*}{ Mode of living } & Urban & 50.0 & $43.1-56.8$ & \multirow[t]{2}{*}{0.787} \\
\hline & Rural & 42.1 & $35.1-49.3$ & \\
\hline \multirow[t]{4}{*}{ BMI Category } & Underweight & 47.1 & $26.0-96.2$ & \multirow[t]{4}{*}{0.762} \\
\hline & Normal weight & 42.2 & $32.5-52.6$ & \\
\hline & Overweight & 47.7 & $37.6-58.0$ & \\
\hline & Obese & 40.2 & $30.5-50.7$ & \\
\hline \multirow[t]{5}{*}{ Educational level } & Illiterate & 35.5 & $25.6-46.7$ & \multirow[t]{5}{*}{0.050} \\
\hline & Primary & 59.1 & $47.0-70.1$ & \\
\hline & Intermediate & 43.9 & $34.8-53.4$ & \\
\hline & Secondary & 52.7 & $39.4-65.3$ & \\
\hline & University and above & 44.3 & $33.8-55.3$ & \\
\hline \multirow[t]{5}{*}{ Occupational status } & Housewife & 48.5 & $40.2-56.8$ & \multirow[t]{5}{*}{0.117} \\
\hline & Employee- Private sector & 40.9 & $29.8-52.9$ & \\
\hline & Employee- Public sector & 53.3 & $43.1-63.1$ & \\
\hline & Laborer & 50.0 & $26.5-73.4$ & \\
\hline & Others & 37.8 & $27.6-49.2$ & \\
\hline \multirow[t]{2}{*}{ Smoking } & Active Smokers & 42.2 & $32.1-52.9$ & \multirow[t]{2}{*}{0.408} \\
\hline & Non-Smokers & 47.3 & $41.8-52.8$ & \\
\hline \multirow[t]{2}{*}{ Khat chewing } & Khat chewers & 46.0 & $35.9-56.4$ & \multirow[t]{2}{*}{0.422} \\
\hline & Non Khat chewers & 46.4 & $40.8-52.0$ & \\
\hline \multicolumn{2}{|l|}{ Overall prevalence } & 46.5 & $41.7-51.4$ & \\
\hline
\end{tabular}

Table 3. Factors associated with H. pylori infection

\begin{tabular}{|c|c|c|c|c|}
\hline \multicolumn{2}{|l|}{ Characteristics } & Positive for HP & Negative for HP & p-value \\
\hline \multirow[t]{2}{*}{ Gender } & Male & $88(45.6)$ & $105(54.4)$ & \multirow[t]{2}{*}{0.765} \\
\hline & Female & $97(47.1)$ & $109(52.9)$ & \\
\hline \multirow[t]{3}{*}{ Age groups (year) } & $13-29$ & $64(53.3)$ & $56(46.7)$ & \multirow[t]{3}{*}{0.034} \\
\hline & $30-49$ & $77(47.0)$ & $87(53.0)$ & \\
\hline & $50+$ & $40(36.4)$ & $70(63.6)$ & \\
\hline \multirow[t]{3}{*}{ Living standard } & High & $14(51.9)$ & $13(48.1)$ & \multirow[t]{3}{*}{0.751} \\
\hline & Medium & $134(47.2)$ & $150(52.8)$ & \\
\hline & Law & $31(43.7)$ & $40(56.3)$ & \\
\hline \multirow[t]{4}{*}{ Endoscopic findings } & Normal & $26(49.1)$ & $27(50.9)$ & \multirow[t]{4}{*}{0.791} \\
\hline & Gastritis & $114(44.0)$ & $145(56.0)$ & \\
\hline & Gastric ulcer & $14(45.2)$ & $17(54.8)$ & \\
\hline & Duodenal ulcer & $8(47.1)$ & $9(52.9)$ & \\
\hline \multirow[t]{4}{*}{ Histopathology findings } & Mild Chronic gastritis & $7(24.1)$ & $22(75.9)$ & \multirow[t]{4}{*}{0.000} \\
\hline & Moderate chronic gastritis & $46(34.8)$ & $86(65.2)$ & \\
\hline & Severe Gastritis & $1(100.0)$ & $0(0.0)$ & \\
\hline & Chronic Active Gastritis & $122(58.1)$ & $88(41.9)$ & \\
\hline
\end{tabular}

\section{Discussion}

The overall prevalence of $H$. pylori among the studied patients was $46.5 \%$, based on real-time PCR. This is in agreement with what was reported in past literature. Ayoola et al. reported a prevalence of 54.9\% among Saudi patients with dyspepsia in the Jazan region of Saudi Arabia in 2004 (14). Another two large studies on Saudi patients have reported prevalence rates of $28 \%$ and $70 \%$, with an average of approximately $50 \%(15,16)$. Alazmi et 
al. reported that the prevalence of $\mathrm{H}$. pylori infection in Kuwaiti patients with dyspepsia was 49.7\% (16). Furthermore, several studies from the Middle East have demonstrated that prevalence ranges between $44 \%$, and $49 \%(17,18)$. In many studies worldwide (United States, Brazil and China), the prevalence of H. pylori among subjects with dyspepsia was $28.9 \%, 57 \%$, and $84 \%$ respectively (19-21). These variations in prevalence rates of $\mathrm{H}$. pylori in different studies across the world might be attributed to different contributing factors including socioeconomic status, living standards, ethnicity and geographical location (22). In addition to the variability in the methods of H. pylori detection, size of the study and exclusion of prior antibiotic use, all these can play roles in these variations. In the present study, the intention was to exclude antibiotics use, but their usage cannot be guaranteed. Despite the lower prevalence of $\mathrm{H}$. pylori infection in developed countries, there are higher rates of gastric carcinoma, contrary to that of developing counties (23). The highest rate of H. pylori infection in this study $(53.3 \%)$ was seen in the age group between $13-29$ years, $47 \%$ among the age group between $30-49$ years and $36.4 \%$ in participants equal to or more than 50 years of age. Many studies have shown the decreased rate of H. pylori infection with an increase in age $(22,24)$. In contrast, other studies have demonstrated positive correlation between H. pylori prevalence rates and increase in age $(25,26)$.

In terms of gender, our findings indicated that, there were no statistically significant differences in the prevalence of H. pylori (45.6\% in males and $47.1 \%$ in females). Some authors reported a high prevalence of H. pylori among females (25). While other authors reported a high rate of $\mathrm{H}$. pylori infection among males, a large number of studies showed no gender differences $(24,27,28)$. A recent meta-analysis study conducted by Zamani, et al in 2018 that involved 183 studies from 73 countries in six continents revealed that although males were predominant of $\mathrm{H}$. pylori infection across all continents, none of the differences reached statistical significance. The issue of gender disparity in $\mathrm{H}$. pylori infection is an intriguing topic and further research is needed to understand the mechanisms by which sex may influence the acquisition and/or persistence of infection (29). In contrast to other reports, our results showed no significant differences in the prevalence rates of $\mathrm{H}$. pylori among different BMI categories $(42.2 \%$ in normal weight, $47.7 \%$ in overweight, and $40.2 \%$ in obese participants). Lender et al. reported an inverse correlation between $\mathrm{H}$. pylori prevalence and the rate of overweight/obesity (30). However, other authors demonstrated positive correlation between $\mathrm{H}$. pylori prevalence rates and overweight/obesity (31). Therefore, the evidence of the role of $\mathrm{H}$. pylori infection in human obesity is inconclusive and controversial (32).

In the present study, we found no difference in the rate of spread of H. pylori in smokers versus non-smokers, ( $42.2 \%$ and $47.3 \%$ respectively). This is in agreement with Khalifa et al. who found no statistically significant difference in H. pylori positivity between smokers and non-smokers (33). It should be mentioned that some arguments about the negative association between smoking and $\mathrm{H}$. pylori infection suggest that the elevated acid and pepsin secretion caused by smoking protects the gastric mucosa from $\mathrm{H}$. pylori infection (34). According to Hassan et al., khat chewing is positively associated with gastritis (35). Many epidemiological studies have suggested that the habit of khat chewing is deeply rooted among the Jazan population, and the current prevalence rate of khat chewing is high at (28.7\%) (36). In the current study, the prevalence rate among khat chewers was $46 \%$, whereas it was $46.4 \%$ in non-khat chewers. Almakdad et al. reported a similar result. He found no relation between khat chewing and high prevalence of $\mathrm{H}$. pylori in Yemeni patients (37). In the current study, the most common endoscopic findings among the $\mathrm{H}$. pylori positive subjects were gastritis (44\%), duodenal ulcer (DU) (52.9\%) and gastric ulcer (GU) (45.2\%), whereas, in H. pylori negative subjects, the rates of gastritis, DU and GU were $56.6 \%, 54.8 \%$ and $52.9 \%$ respectively. So we did not find association between these endoscopic findings and H. pylori. This is in disagreement with Mohammed et al. and Ayana et al. who found significant correlation between endoscopic findings and $\mathrm{H}$. pylori $(38,39)$. However, some authors reported no or poor correlation between endoscopic findings and histological diagnosis $(40,41)$. These differences may be attributed to other contributing factors including socioeconomic status, living standards, ethnicity and geographical location. In the present study, the most common histopathological finding was chronic active gastritis (CAG), which was found in $58.1 \%$ of $\mathrm{H}$. pylori positive subjects, compared to $41.9 \%$ of $\mathrm{H}$. pylori- negative ones. In the current study, CAG was significantly associated with $\mathrm{H}$. pylori, and is a good suggestion for the causative role of $\mathrm{H}$. pylori in chronic active gastritis. Many clinical studies reported that $\mathrm{H}$. pylori is significantly associated with $\mathrm{CAG}$, atrophic gastritis, intestinal metaplasia and gastric cancer $(42,43)$.

\section{Study limitation}

The present study has some limitations; first, the study sample may not be representative of the population of Jazan, since the sampling technique was a purposive sampling without randomization. Second, a cross-sectional study design is not suitable for assessing risk factors for H. pylori. Third, no controls were included as the study relied on 
the invasive method of H. pylori detection. Despite these limitations, the study provided updated information on the status of $\mathrm{H}$. pylori in Jazan province.

\section{Conclusions}

In conclusion, the prevalence of $\mathrm{H}$. pylori among patients with dyspepsia in the Jazan region is high, especially in age groups below 55 years. No correlation was found between endoscopic findings and H. pylori positivity. Chronic active gastritis was significantly associated with $\mathrm{H}$. pylori. The results of this study provide important implications for public health strategies for the prevention of $\mathrm{H}$. pylori infection in the Jazan region. In depth studies are needed to determine the factors associated with H. pylori infection in the region.

\section{Acknowledgments:}

This research received financial support from King Abdulaziz City for Science and Technology (KACST), grant number ARP-47-32; for 20 months under the annual grant program. We express our deep gratitude to KASCT for the financial and technical support of this research. Gratitude is extended to our colleagues in gastrointestinal units at general hospitals in the Jazan region for their technical support. We are also immensely grateful to Mohammed Awad and Ahmed Saad for their technical support.

\section{Conflict of Interest:}

There is no conflict of interest to be declared.

\section{Authors' contributions:}

MA, EE, AS, ASE, HA and TA conceptualized and designed the research project, and carried out the practical work. MSM performed the statistical analysis and finalized the manuscript. All authors provided significant input in the manuscript, and read and approved the final version of it.

\section{References:}

1) Warren JR, Marshall B. Unidentified curved bacilli on gastric epithelium in active chronic gastritis. The Lancet. 1983; 321(8336): 1273-5. doi: 10.1016/S0140-6736(83)92719-8.

2) Essawi T, Hammoudeh W, Sabri I, Sweidan W, Farraj MA. Determination of Helicobacter pylori virulence genes in gastric biopsies by PCR. ISRN Gastroenterol. 2013; 2013.

3) Pounder RE, Ng D. The Prevalence of Helicobacter pylori infection in Different Countries. Aliment Pharmacol Ther .1995; 9(Suppl 2): 33-39. PMID: 8547526.

4) Bytzer P, Dahlerup JF, Eriksen JR, Jarbøl DE, Rosenstock S, Wildt S. Diagnosis and treatment of Helicobacter pylori infection. Dan Med Bull. 2011; 58(4): C4271. PMID: 21466771.

5) Al-Akwaa AM. Prevalence of Helicobacter pylori infection in a group of morbidly obese Saudi patients undergoing bariatric surgery: A preliminary report. Saudi J Gastroenterol. 2010; 16: 264-7. doi: 10.4103/1319-3767.70610. PMID: 20871190, PMCID: PMC2995094.

6) Hasosah M, Satti M, Shehzad A, Alsahafi A, Sukkar G, Alzaben A, et al. Prevalence and Risk Factors of Helicobacter pylori Infection in Saudi Children: A Three - Year Prospective Controlled Study. Helicobacter. 2015; 20(1): 56-63. doi: 10.1111/hel.12172. PMID: 25495104.

7) de Martel C, Ferlay J, Franceschi S, Vignat J, Bray F, Forman D, et al. Global burden of Cancer attributable to H. pylori infection: a review and synthetic analysis. Lancet Oncol. 2013; 3(6): 607-15. doi: 10.1016/S1470-2045(12)70137-7. PMID: 22575588.

8) Dixon MF. Pathology of gasitritis and peptic ulceration. In: Mobley HLT, Mendz GI, Hazell: H. pylori: Physiology and Genetics. Washington DC: ASM Press; 2001.

9) Wang HC, Cheng FC, Wu MS, Shu HY, Sun HS, Wang YC, et al. Genome sequences of three Helicobacter pylori strains from patients with gastric mucosa-associated lymphoid tissue lymphoma. Genome announcements. 2015; 30; 3(2): e00229-15.

10) Souod N, Sarshar M, Dabiri H, Momtaz H, Kargar M, Mohammadzadeh A, et al. The study of the oipA and dupA genes in Helicobacter pylori strains and their relationship with different gastroduodenal diseases. Gastroenterol Hepatol Bed Bench. 2015; 8(Suppl1): S47-53. PMID: 26171137, PMCID: PMC4495424.

11) Al-Moagel MA, Evans DG, Abdulghani ME, Adam E, Evans DJ Jr, Malaty HM, et al. Prevalence of Helicobacter (formerly Campylobacter) pylori infection in Saudi Arabia, and comparison of those with and without upper gastrointestinal symptoms. Am J Gastroenterol. 1990; 85(8): 944-948. PMID: 2375321.

12) Marie MA. Seroprevalence of Helicobacter pylori Infection in Large Series of Patients in an Urban Area of Saudi Arabia. Korean J Gastroenterol. 2008; 52: 226-9. PMID: 19077524. 
13) Iman N, Khan H, Iqbal S, Rehman S. Frequency of H. pylori in patients with upper G.I symptoms. J Med Sci. 2008; 16(1): 1-3.

14) Ayoola AE, Ageely HM, Gadour MO, Pathak VP. Prevalence of Helicobacter pylori infection among patients with dyspepsia in South- Western Saudi Arabia. Saudi Med J. 2004; 25(10): 1433-8. PMID: 15494817.

15) Momenah A, Tayeb MH. Helicobacter pylori cagA and iceA genotypes staus and risk of peptic ulcer in Saudi patients. Saudi Med J. 2007; 28(3): 382-5.

16) Alazmi WM, Siddique I, Alateeqi N, Al-Nakib B. Prevalence of Helicobacter pylori infection among Kuwaiti patients with dyspepsia. BMC Gastroenterol. 2010; 10: 14. doi: 10.1186/1471-230X-10-14. PMID: 20128917, PMCID: PMC2835643.

17) Tanih NF, Okeleye BI, Ndip LM, Clarke AM, Naidoo N, Mkwetshana N, et al. Helicobacter pylori prevalence in dyspeptic patients in the Eastern Cape province: race and disease status. S Afr Med J. 2010; 100(11): 734-7. doi: 10.7196/SAMJ.4041. PMID: 21081026.

18) Chong VH, Lim KC, Rajendran N. Prevalence of active Helicobacter pylori infection among dyspeptic patients referred for endoscopy in Brunei Darussalam. Singapore MED J. 2008; 49: 42-6. PMID: 18204768 .

19) Shokrzadeh L, Baghaei K, Yamaoka Y, Shiota S, Mirsattari D, Porhoseingholi A, et al. Prevalence of Helicobacter pylori infection in dyspeptic patients in Iran. Gastroenterology Insight. 2012; 4: e8. doi: 10.4081/gi.2012.e8.

20) Replogle ML, Glaser SL, Hiatt RA, Parsonnet J. Biologic sex as a risk factor for Helicobacter pylori infection in healthy young adults. Am J Epidemiol. 1995; 142(8): 856-63. doi: 10.1093/oxfordjournals.aje.a117725. PMID: 7572962.

21) Ramis IB, Vianna JS, Silva Junior LV, Von Groll A, Silva PE. CagE as a biomarker of the pathogenicity of Helicobacter pylori. Rev Soc Bras Med Trop. 2013; 46(2): 185-9. doi: 10.1590/0037-8682-0054-2012. PMID: 23740068.

22) Aziz F, Chen X, Yang X, Yan Q. Prevalenceand Correlation with Clinical Diseases of Helicobacter pylori cagA and vacA Genotype among Gastric Patients from Northeast China. Biomed Res Int. 2014; 2014 : 142980. doi: 10.1155/2014/142980. PMID: 24949419, PMCID: PMC4052682.

23) Ashtari S, Pourhoseingholi A, Molaei M, Taslimi H, Zali M. The prevalence of Helicobacter pylori is decreasing in Iranian patients. Gastroenterol Hepatol Bed Bench. 2015; 8(Supp11): S23-9. PMID: 26171134, PMCID: PMC4495420.

24) Ahmed SM, Hussein A, Ali M, Ali E, Mekky WM, Abdel-Fattah HM, et al. The Prevalence of Cag-A and Vac-A Genotypes among Helicobacter pylori Infected Egyptian Patients. The ASM. 114th General Meeting of the American Society for Microbiology Boston: USA; 2014.

25) Pajavand H, Alvandi A, Mohajeri P, Bakhtyari S, Bashiri H, Kalali B, et al. High Frequency of vacA s1m2 Genotypes Among Helicobacter pylori Isolates From Patients With Gastroduodenal Disorders in Kermanshah. Jundishapur J Microbiol. 2015; 8(11). doi: 10.5812/jjm.25425. PMID: 26862378, PMCID: PMC4740511.

26) Essawi T, Hammoudeh W, Sabri I, Sweidan W, Farraj M. Determination of H. pylori virulence genes in gastric biopsies by PCR. Gastroenterol. 2013.

27) Nguyen T, Ramsey D, Graham D, Shaib Y, Shiota S, Velez M, et al. The Prevalence of Helicobacter pylori Remains High in African American and Hispanic Veterans. Helicobacter. 2015; 20(4): 305-11. doi: 10.1111/hel.12199. PMID: 25689684.

28) Kadi R, Halawani E, Abdelkader H. Prevalence of H. pylori strains harbouringcag A and iceA virulence genes in Saudi patients with gastritis and peptic ulcer disease. Microbiology discovery. 2014.

29) Zamani M, Ebrahimtabar F, Zamani V, Miller WH, Alizadeh - Navaei R, Shokri - Shirvani J, et al. Systematic review with meta - analysis: the worldwide prevalence of Helicobacter pylori infection. Alimentary pharmacology \& therapeutics. 2018; 47(7): 868-76. doi: 10.1111/apt.14561. PMID: 29430669.

30) Lender N, Talley NJ, Enck P, Haag S, Zipfel S, Morrison M, et al. Review article: Associations between Helicobacter pylori and obesity--an ecological study. Aliment Pharmacol Ther. 2014; 40(1): 24-31. doi: 10.1111/apt.12790. PMID: 24832176.

31) Xu C, Yan M, Sun Y, Joo J, Wan X, Yu C, et al. Prevalence of Helicobacter pylori infection and its relation with body mass index in a Chinese population Helicobacter. 2014; 19(6): 437-42. doi: 10.1111/hel.12153. PMID: 25256639. 
32) Kyriazanos ID1, Sfiniadakis I, Gizaris V, Hountis P, Hatziveis K, Dafnopoulou A, et al. The incidence of Helicobacter pylori infection is not increased among obese young individuals in Greece. J Clin Gastroenterol. 34: 541-6. doi: 10.1097/00004836-200205000-00012. PMID: 11960066.

33) Khalifa M, Khodair S, Almakdad A. Cigarette smoking status and H. pyloriinfection in non-ulcer dyspepsia patients. Egyptian Journal of chest diseases and tuberculosis. 2014; 63(3): 695-99. doi: 10.1016/j.ejcdt.2014.03.007.

34) Ogihara A, Kikuchi S, Hasegawa A, Kurosawa M, Miki K, Kaneko E, Mizukoshi H. Relationship between Helicobacter pylori infection and smoking and drinking habits. Journal of gastroenterology and hepatology. 2000; 15(3): 271-6. doi: 10.1046/j.1440-1746.2000.02077.x. PMID: 10764027.

35) Hassan M, Mohammed K, Zipporah N, Husdson L. Khat (Catha edulis) use is associated with the development of gastritis among adults in Nairobi Kenya. East Afr Med J. 2014; 91(6).

36) Mahfouz MS, Rahim BE, Solan YM, Makeen AM, Alsanosy RM. Khat chewing habits in the population of the Jazan Region, Saudi Arabia: prevalence and associated factors. PloS one. 2015; 10(8): e0134545.

37) Almakdad A, Aldohlae M, Thabet A, Alhaimi M, Bafaqih O, Alhadad A. Prevalence of H. pylori infection in Yemeni patients. Yemeni Journal for Medical Sciences. 2013; 7.

38) Mohammed MO. Correlation of Endoscopic Findings with Various Helicobacter pylori Tests among Dyspeptic Patients. Int J Clin Med. 2014; 9; 5(19): 1180-8.

39) Ayana S, Sawi B, Venance B, Kibiki G. Upper GI endoscopic findings and prevalence of H. pylori infection among adult patients with dyspepsia in Northern Tanzania. Tanzan J Health Res. 2014; 16(1).

40) Al-Hamdani A, Fayady M, Majed B. H.pylori gastritis: Correlation between the endoscopic and histological findings. IJGE. 2001; 2001: (1).

41) Puodal A, Regmi S, Poudal S, Joshi P. Correlation between endoscopic and histopathological findings in gastric lesions. Journal of University college of Medical Sciences. 2013: 1(3).

42) Yakoob M, Hussainy A. Chronic gastritis and H.pylori: A histopathological study of gastric mucosal biopsy. J Coll Physicians Surg Pak .2010; 20(11): 773-5. PMID: 21078257.

43) Olmez S, Aslan M, Erten R, Sayar S, Bayram I. The prevalence of gastric intestinal metaplasia and distribution of helicobacter pylori infection, atrophy, dysplasia, and cancer in its subtypes. Gastroenterol Res Pract. 2015; 2015: 434039. doi: 10.1155/2015/434039. PMID: 26635875, PMCID: PMC4655281. 